\title{
Capuchinos bávaros y niñez mapuche: aproximaciones desde la Fenomenología del cuerpo en Merleau Ponty ${ }^{1}$
}

\section{Bavarian capuchins and mapuche childhood: approaches from the Phenomenology of the body in Merleau Ponty}

Juan Mansilla SEPÚLVEDA²

Daniel Quilaqueo RAPIMÁN³

\begin{abstract}
Resumen
La fenomenología del cuerpo de Merleau Ponty nos entrega herramientas que nos permiten pensar de otro modo el montaje del aparato disciplinario que llevaron a cabo diversos agentes hacia los pueblos originarios a fines del siglo XIX en Chile. La integración forzosa de la Araucanía da inicio a un proceso de ocupación de tierras donde terminan imponiéndose los proyectos modernizadores que propiciaban los grupos dirigentes de Chile y la consiguiente política inmigratoria promovida desde el Estado. Llegan a la Araucanía por solicitud de las elites chilenas la congregación de monjes capuchinos bávaros y las Hermanas Maestras de la Santa Cruz.
\end{abstract}

Palabras-Clave: Fenomenología del Cuerpo. Escuela Monocultural. Niñez Mapuche. Capuchinos Bávaros.
Abstract

The phenomenology of the body of Merleau Ponty gives us a series of tools that allow us to think in a different way about the assembly of the disciplinary apparatus carried out by various agents towards the indigenous peoples at the end of the 19th century in Chile. The forced integration of the Araucanía begins a process of occupation of lands where the modernizing projects favored by the leading groups of Chile and the consequent immigration policy promoted by the State end up being imposed. The congregation of Bavarian Capuchin monks and the Teacher Sisters of the Holy Cross arrive at the Araucanía at the request of the Chilean elites.

Keywords: Phenomenology of the Body. Monocultural School. Mapuche Childhood. Bavarian Capuchins.

1 El presente artículo forma parte de los resultados del Proyecto CONICYT/FONDECYT Regular $\mathrm{N}^{\circ}$ 1160409, titulado "Historia y memoria de la escuela monocultural en la Araucanía (siglos XIX y XX).

2 Doctor en Filosofía y Letras por la Universidad Pontificia de Salamanca, Espańa. Profesor del Programa de Doctorado en Educación de la Universidad Católica de Temuco. Decano de la Facultad de Educación, Universidad Católica de Temuco. Director de la Revista Educadi. Tel. (56) 978478454. Email: <jmansilla@uct.cl>

3 Doctor en Sociología por la Université de la Sorbonne Nouvelle, Paris III, Francia. Director del Programa de Doctorado en Educación de la Universidad Católica de Temuco. Director del Centro de Investigación en Educación en Contexto Indígena e Intercultural, CIECII. Tel. (56) 990018051. Email: <dquilaq@uct.cl>

\begin{tabular}{|l|l|l|l|l|l|} 
R. Educ. Públ. & Cuiabá & v. 27 & n. $65 / 2$ & p. $733-751$ & maio/ago. 2018 \\
\hline
\end{tabular}




\section{Introducción}

La investigación que se presenta hace referencia a las posibilidades analíticas que nos ofrecen las relaciones intersubjetivas que se produjeron entre los misioneros bávaros capuchinos y niños y niñas mapuche a comienzos del siglo $\mathrm{XX}$, a partir de los aportes fenomenológicos del filósofo francés Merleau Ponty. Nuestra intención es proponer un diálogo intercultural e intersubjetivo sobre las corporalidades indígenas presentes en los vestigios fotográficos encontrados en los archivos capuchinos en Baviera (Alemania), utilizando el enfoque teórico de la fenomenología del cuerpo.

En la segunda mitad del siglo XIX, el Estado chileno incorporó por la fuerza al territorio nacional el espacio denominado Araucanía, ocupado ancestralmente por el pueblo mapuche. La integración de la Araucanía a Chile da inicio a un proceso de ocupación de tierras donde terminan imponiéndose los proyectos modernizadores que propiciaban los grupos dirigentes del centro del país y la consiguiente política inmigratoria promovida desde el Estado. (MANSILLA, LLANCAVIL, MIERES; MONTANARES, 2016). En este contexto las congregaciones religiosas desempeñaron un papel relevante para que los indígenas superaran el "paganismo" y la "ignorancia", y por tanto, sean educados, "civilizados" al amparo de la educación occidental. Entonces, surge la triada escuela-misióninternado promovida por los capuchinos bávaros para materializar este discurso civilizatorio del Estado nacional y lograr someter el cuerpo del otro totalmente.

En este proceso fue fundamental construir una imagen del "otro" como un salvaje al que se debía civilizar y difundir por el mundo a través de tarjetas postales y fotografías aquellos cuerpos que estaban en procesos de disciplinamiento en las diversas escuelas de la Araucanía (TODOROV, 1992). Aquí el concepto civilización se simboliza por un conjunto de atributos considerados positivos tales como: "Europa, ciudad, occidente, espíritu, luz, racionalidad, familia, escuela, higiene, sabiduría, amor, día, belleza, cristianismo, blanco, bueno, sano, limpio, progreso, etc. Mientras que barbarie fue la noción maestra que englobó un conjuntos de términos directamente negativos, entre los cuales están "América, campo, cuerpo, oscuridad, mapuche, poligamia, instinto, ignorancia, odio, noche, tinieblas, fealdad, paganismo, negro, malo, enfermo, sucio, atraso, etc." (DE LA BARRA, 2000; AZÓCAR, NITRIHUAL, FLORES, LÓPEZ Y PACHECO, 2015).

En este marco resulta pertinente generar intersecciones de reflexión teórica, ética y política a partir de los aportes filosóficos de Maurice Merleau Ponty, quien restableció el papel fundamental del cuerpo en la intelección del ser del hombre, 
precisamente para solucionar el problema en que se sitúa la pérdida de su misma apropiación (GONZÁLEZ Y JIMÉNEZ, 2010). Merleau Ponty no ha sido suficientemente estudiado en Chile, no obstante siempre ha sido un "desconocido presente". Esta condición de "desconocido presente" se debe a la discreción del filósofo. Merleau Ponty trabaja en los pliegues más que en los centros, esto explica su "devenir imperceptible" en el recorrido de la filosofía francesa contemporánea al decir de Deleuze. Merleau Ponty, fue maestro de Foucault y de Deleuze, que tiempo después irrumpirán con un lenguaje nuevo y con fuertes desplazamientos de los objetos de los que se ha preocupado tradicionalmente la filosofía. Esto queda bastante bien ilustrado con las primeras palabras de Merleau Ponty en ese libro inacabado que se denomina "La Prosa del mundo", dice MERLEAU PONTY (1969, p. 25) "[...] Hace mucho tiempo que se habla sobre la tierra, y las tres cuartas parte de los que se habla pasan inadvertidas. Una rosa, llueve, hace un tiempo hermoso, un hombre mortal".

El planteamiento de Merleau Ponty es deudor de las tesis de Edmund Husserl, quien generó un método fenomenológico fundamental para comprender el mundo de la vida, la alteridad, el cuerpo vivenciado y la intersubjetividad que resulta de este choque cultural, en este caso entre el ethos bávaro-alemán y el ethos indígenamapuche. El método fenomenológico consiste en un conjunto de procedimientos que pretenden alcanzar una descripción no distorsionada de la experiencia. Se inicia con una reducción eidética o epoché que consiste en intentar abstraer de la experiencia original los elementos reflexivos que introducimos a posteriori en el mismo producto de la actitud natural (TAYLOR, 1995; HUSSERL, 2002).

En este escenario, se pretende evidenciar cómo, a partir del estudio del concepto cuerpo podemos comprender y pensar las relaciones interculturales e intersubjetivas entre misioneros y niños y niñas mapuche, teniendo como campo cristalizador de esas relaciones los dispositivos escuela, misión e internados. Por tanto, esta ontología del ser sensible que se nos abre a partir de Merleau-Ponty resulta oportuna e interesante, aun cuando algunas categorías de este pensador sean calificadas por algunos filósofos como de "repeluz".

Consideramos que la fenomenología del cuerpo de Merleau Ponty abre un nuevo horizonte para comprender la dimensión corpórea de la existencia humana y ofrece una nueva visión filosófica del cuerpo, en tanto que el cuerpo no es sólo una realidad observable como objeto, sino que es una dimensión del propio ser, pues como lo plantea Merleau-Ponty, desde la fenomenología de la 'existencia corpórea', el cuerpo es el 'medio' de nuestro 'ser-hacia-el-mundo' (GALLO, 2006). Este posicionamiento implica abandonar ese modo de pensar desde el sobrevuelo, de distancia del mundo y de conciencia separada del mundo. En todo momento, desde Merleau Ponty, la visión es recíproca aunque lo que esté 
en frente o con nosotros no tenga ojos. Lo visible del mundo es precisamente aquello que se da en una relación recíproca. Ver es ser visto, o por lo menos ser visible. Hacer filosofía es reaprender a ver el mundo, y esto no es construir nuevas imágenes del mundo, sino reaprender a ver el mundo, es ponerse en otro lugar.

\section{La distinción entre körper y leibs en Husserl: Prehistoria de las capas analíticas de Merleau Ponty}

El “ $k$ örper" en tanto cuerpo-cosa -tenido-pensado-objetivo, situado desde una actitud naturalista, es la presencia física, es la existencia en el mundo físico que se manifiesta, en primera instancia, como una cosa entre las cosas de la naturaleza. El cuerpo, en cuanto a cosa como cualquier otra, admite una serie de causalidades que pertenecen a las cosas, por ejemplo, tiene una masa y ocupa un espacio; el cuerpo es una cosa física, con tal o cual contextura, tiene vivencias y disposiciones vivenciales y tiene particularidades: camina así, se mueve así. El cuerpo-objeto se manifiesta como cosa en el espacio y en el tiempo, comparte las mismas características y determinaciones que la totalidad de los objetos en la naturaleza (WALDENFELS, 2000). Por otra parte, el "leib" cuerpo propio-vivido-fenomenal-animado-agente-subjetivo, situado desde una actitud personalista, es un cuerpo-sujeto, fungiente, sintiente, ser-cuerpo, es el cuerpo-propio. El cuerpo fungiente se refiere al cuerpo que hace algo, que aparece como sujeto-agente en el 'yo puedo'; es decir, el cuerpo que "[...] en el percibir, en el accionar, en el sentir, en la sexualidad, efectúa un rendimiento, ejerce una función" (WALDENFELS, 2000, p. 42; HUSSERL, 1997). En clave fenomenológica, el cuerpo no es un objeto que se pueda concebir y tratar como una cosa ni como algo puramente material, ya que es una dimensión de mi propia existencia. El cuerpo-propio, fenomenal, hay que considerarlo como el sujeto encarnado que está presente en el mundo. En este campo analítico, Merleau-Ponty utiliza como categoría el 'quiasmo' que lo entiende como "un esquema de pensamiento que nos permite concebir las relaciones de una dualidad en términos de reciprocidad, entrecruzamiento, complementariedad, sobreposición, encabalgamiento, reversibilidad, mutua referencia. Todo lo contrario a los esquemas dicotómicos y dualistas, que conciben las relaciones en términos de exclusión, exterioridad, causalidad mecánica y lineal, jerarquía $y$ prioridad. El esquema del quiasmo es lo que nos permite pensar a la dualidad como una unidad en proceso, en devenir (RAMÍREZ, 1994, p. 47).

Al distinguir entre los objetos y el cuerpo, señalando la doble condición de este último como natural (Körper) y como cuerpo vivido (Leib), el alma 
aparece representada no como un conjunto de vivencias desligadas del cuerpo, sino la unidad real que se manifiesta en ellas; de modo que lo anímico está entrelazado con lo corporal, pero el carácter subjetivo del cuerpo no se debe al alma o al psiquismo, sino al yo-sujeto de la intencionalidad (BRAND, 1971; HUSSERL, 1997; SERRANO DE HARO, 1997). Para Husserl, la experiencia de la mano es clave para entender la constitución del cuerpo propio (HUSSERL, 1997), mientras que a los ojos de Merleau-Ponty es el signo que manifiesta la imposibilidad de una constitución completa. Ambos filósofos concuerdan en esto, pero mientras que para Husserl esa imperfección constitutiva exige profundizar en el sentido de la subjetividad constituyente; según MerleauPonty, esa "incompletitud" cuestiona la idea misma de constitución, el poder de la conciencia, y conduce a describir los fenómenos a partir de la experiencia perceptiva (RAMOS, 2015). La originalidad del fenomenólogo francés consiste, por un lado, en partir del sentido de las experiencias táctil y visual para cuestionar la idea de constitución y de conciencia constituyente, y, por otro, considerar la relación tocante-tocado a partir del modelo de la visión. Si en el pensamiento de Merleau-Ponty cabe hablar de cierto privilegio de la experiencia visual frente a la táctil es porque, frente a la inmediatez que requiere el tacto, la visión introduce, como acabamos de decir, una proximidad distante que es fundamental para pensar la simultaneidad: esta, indisociable del movimiento, permite afirmar la presencia y la apertura corporales del sujeto y del mundo y prohíbe las dualidades (conciencia-mundo, sujeto-objeto, interioridad-exterioridad) introducidas por la idea de constitución. (RAMOS, 2015). Dado que el único modo de conocer el cuerpo, ya sea el mío o el de otro, es vivirlo; no es el sujeto epistemológico el que efectúa la síntesis, sino el cuerpo cuando con todos los medios se dirige a un término único de su movimiento y cuando se concibe en él una intención única mediante el fenómeno de sinergia (RAMOS, 2015).

El núcleo de la preocupación merleau-pontiana es ese dinamismo (eksistere) en que el cuerpo trasciende su corporalidad aquí y ahora, su dimensión de $k$ örper o cuerpo-objeto, para alcanzar una existencia significativa que a la vez arraiga en la vida corporal o leib (RAMOS, 2015). En consecuencia, el cuerpo está por encima de la res extensa, pero por debajo de la res cogitans, pues su presencia a sí es ausencia de sí y su interioridad es la de un "se" (BARBARAS, 1998).

Según Merleau Ponty sólo desde el estudio profundo del cuerpo a través de las percepciones que permiten la relación entre la interioridad humana y el mundo exterior es posible conocer y comprender la humanidad del hombre. Esta perspectiva nos sitúa en una dimensión ontológica y fenomenológica. En 
este contexto, la percepción no es una ciencia del mundo, sino el trasfondo sobre el que se destacan todos los actos y que todos los actos presuponen (MERLEAU-PONTY, 2000),

Esta noción de la percepción a partir del ser/estar corporalmente en el mundo es un desafío a las concepciones dualistas que enfatizan distinciones sujetoobjeto, interior-exterior, mental-físico y mente-mundo. Argumentar a favor de una concepción de la existencia humana inextricable de su corporalidad, implica poner en entredicho la primacía de la conciencia y problematizar la distinción entre primera y tercera persona.

A fin de superar la imagen representacionalista del conocimiento, Merleau-Ponty propone encarar el misterio filosófico de la percepción desde dos ángulos. Por un lado, el hecho de que el mundo se nos revela haciéndonos partícipes a través de su proximidad y su distancia. Por otro lado, nuestro encuentro con el mundo no puede ser reducido a un mero procesamiento informativo de data, ni podemos concebirnos a nosotros mismos como una aparición flotante sobre la superficie de las cosas.

Es erróneo concebir nuestra corporalidad como una mera posesión del yo de su cuerpo, del mismo modo que es erróneo concebir al yo en posesión de una mente. De manera análoga, es erróneo concebir el mundo como una posesión de las subjetividades. El cuerpo, la mente y el mundo, para decirlo de algún modo, son inherentes, constitutivos de los seres humanos.

Por tanto, como hemos indicado, la fenomenología de Merleau-Ponty no pretende ser un ejercicio analítico de la percepción, sino más bien un esfuerzo por describir la percepción y el cuerpo de un modo radical y apodíctico.

El cuerpo es una manifestación de un mundo en el que, paradójicamente, nos sitúa; por esto se comporta a la vez como perceptor y percibido. En cuanto que está polarizado por sus tareas, pues existe en ellas, mi cuerpo es una figura del mundo que se expresa en el esquema corporal, ya que este se ha de entender como "una toma de consciencia global de mi postura en el mundo intersensorial.

Profundizando en la distinción entre espacialidad de situación y de posición (pues mi cuerpo no está en el espacio sino que es espacial o espacializante), el hábito nos hace ver que el espacio no es aprendido, sino vivido como una modulación de mi relación corporal con el mundo. Por tanto, en la medida en la que ser cuerpo significa estar situado, Merleau-Ponty prioriza el espacio topológico, el espacio de un paisaje, antes que el geométrico o el espacio entendido como un campo previo de acción (MERLEAU PONTY, 1998)

Si el espacio que corresponde a las cosas es "posicional", la espacialidad de mi cuerpo es "situacional" y consiste en la unidad de posibilidades prácticas que orientan el espacio objetivo según intenciones precisas. Aun estando separada de las cosas por el espesor de la mirada y del cuerpo, esta distancia sintoniza y 
sincroniza con la proximidad de las cosas en su sitio, según su ser que excede el ser percibido. Sin cuerpo, no habría espacio para mí; aunque sin la forma universal del espacio no habría para nosotros el espacio corpóreo.

El cuerpo es, además, espacializante. Su espacialidad no es de posición, sino de situación, pues se trata de un espacio cualitativo de implicación y de expresión desde el cual va a manifestarse un espacio que, por consiguiente, siempre es subjetivo-objetivo (FERNANDEZ-BEITES, 1999).

La "reflexión" de la experiencia de la mano que se siente tocada al tocar comienza mostrando la reflexividad del cuerpo, pero en "el filósofo y su sombra" Merleau-Ponty la hace extensiva al otro, pues al igual que mis manos pertenecen al mismo cuerpo, otro y yo somos miembros de la misma corporeidad; por último, en Lo visible y lo invisible, la relación tocante-tocado se generaliza y deviene el suelo de una ontología que a partir del movimiento busca pensar el mundo y el Sí

La espacialidad y la temporalidad del propio cuerpo. La fenomenología al entender el cuerpo propio en su ser-en-el-mundo demanda de una apertura del cuerpo que tiene como base la espacialidad, no de posición sino de situación, porque nunca podré observar mi propio cuerpo como podría observar una realidad ajena a mí. La temporalidad en la fenomenología no puede ser considerada una propiedad 'objetiva', sino que es precisamente por mediación de la subjetividad que se pronuncia sobre el mundo, es el tiempo subjetivo del ser-en-el-mundo el que adquiere diferentes significados en el mundo de la vida (Lebenswelt). La principal razón que tiene la fenomenología para entender el espacio y el tiempo como dimensiones de lo 'vivido' y no como propiedades 'objetivas', es porque no podemos observar nuestro cuerpo del modo como lo hacemos con los objetos del mundo circundante (MERLEAU PONTY, 1969). El cuerpo como intersubjetividad-intercorporalidad. El sujeto encuentra en el mundo circundante no solamente cosas sino, también, otros sujetos que ve como personas y no las trata como una mera cosa porque hacen parte del mundo circundante común, y los actos surgen para un comportamiento como miembros de un todo enlazado, actúan en común y no sólo individualmente; actúan, pues, personalmente enlazados, social y culturalmente. En la experiencia constitutiva del cuerpo, tiene que ver la relación en cuanto a los otros sin cuya aportación co-constituyente no habría mundo objetivo (LANDGREBE, 1968; WALDENFELS, 1997). Del mismo modo, dice Waldenfels (1997, p. 38) que "la subjetividad pasa a la esfera intermedia de la intersubjetividad, un 'Entre' (Zwischen) como lo llama Martin Buber, un 'mundo intermedio' (intermonde), como lo llama Merleau-Ponty, un 'reino intermedio' (Zwischenreich) como yo lo he llamado, que pertenece a todos y a ninguno en particular (BUBER, 1993). 


\section{Cuerpos de niños mapuche y la escuela capuchina en la Araucanía}

La escuela lo que busca es disciplinar no sólo el alma, sino también el cuerpo, encauzarlo por senderos de normalidad a partir de reglamentos y dispositivos diversos: unos más directos y soberanos, otros más indirectos y sutiles (FOUCAULT, 2002). En un plano individual, el resultado son sujetos dóciles y disciplinados. A escala global, a fines del siglo XIX y comienzos del $\mathrm{XX}$ en el sur de Chile el telos constituyente de la escuela fue consolidar un proyecto de estado nación de Chile con una idea de educación monocultural.

Desde este posicionamiento, la cuestión educativa en Chile históricamente ha sido pensada aislando el cuerpo de toda reflexión e investigación, reduciendo su abordaje al campo de la motricidad humana. Por consiguiente, esta perspectiva pedagógica es profundamente dualista ya que ha puesto su interés hegemónico en la relación cuerpo-mente, cuya premisa indica que es la mente la facultad más importante en educación. Los discursos, imágenes y prácticas que moldearon el cuerpo desde finales del siglo XIX hasta llegar a mediados del siglo XX en Chile se insertaron en la escuela con la finalidad de producir cierto tipo de sujeto: el ciudadano chileno occidentalizado (MAYORGA, 2017)

Desde esta óptica, la escuela se configura como una de las instituciones donde se forja un proyecto biopolítico mediante el cual los Estados-nación dan forma a una ciudadanía que, en últimas, encarna la necesidad de salir del rezago y la barbarie (HOBSBAWM, 1998).

En este orden de cosas, en el sistema escolar, la mayoría de los temas vinculados con el cuerpo se sitúan desde la educación física, deporte, recreación y ámbitos vinculados con las denominadas actividades curriculares de libre elección correspondiente al curriculum complementario, tales como teatro, danza, bailes, entre otros. Difícilmente encontraremos investigaciones empíricas o reflexiones epistemológicas que estudien el cuerpo en la clase de historia y geografía, química o matemáticas, lo que evidencia que el foco de la analítica del cuerpo se correlaciona con el movimiento del mismo. Desde este hecho, la educación física revistió gran importancia en la constitución de las subjetividades que esperaba la escuela, así como en la consolidación del proyecto de nación que se promovió a comienzos del siglo XX en la Araucanía desde el aparato educativo que transmitieron los capuchinos bávaros y las hermanas de la Santa Cruz (MANSILLA Y HUAIQUIÁN, 2018).

Desde el punto de vista de las reflexiones teóricas desarrolladas desde las ciencias sociales, estas generalmente asumen un posicionamiento crítico 
respecto al rol que ha desempeñado la institución escolar en la constitución de ciertas formas de subjetividad y en el disciplinamiento de los cuerpos. Mayoritariamente, este acervo de estudios se fundamenta en el pensamiento de Michel Foucault, y desarrolla varios de sus postulados en relación con el cuerpo, partiendo de la idea inicial de que este constituye el lugar del ejercicio del poder, así como de la acción de las disciplinas que derivan en la formación de sujetos particulares (FOUCAULT, 2008; CABRA Y ESCOBAR, 2013). En este orden de cosas, la escuela emerge como parte del sistema panóptico que vigila, castiga y organiza los cuerpos para establecer un cierto orden productivo. De igual manera, aparece como generadora de marcadores de género, clase y jerarquías en torno al cuerpo, teniendo como eje de estas acciones su consolidación como escenario privilegiado de la relación saberpoder. En este diagrama soberano "la escuela es un aparato, un saber y un campo de visibilidad. Estas funciones se refieren a la enseñanza y a los sujetos que en esta confluyen y al control sobre los mismos" (FOUCAULT, 2008; RECIO, 2009, p. 133).

En este sentido, el cuerpo se concibe como un ordenamiento que condiciona lo que está bien y es aceptable desde la lógica de la productividad, y define lo que es anormal y debe ser castigado. Desde esta perspectiva, esta vertiente de reflexión plantea cómo la escuela traza un espacio que distribuye y circunscribe los cuerpos, y que define ciertas relaciones con otros cuerpos y con los objetos. El lugar donde está el cuerpo no solo lo sitúa, sino que genera formas determinadas de comprenderlo, percibirlo y apropiarlo. Para la fenomenología, el espacio no es un vacío que contiene los cuerpos y los determina, sino que uno y otro se encuentra vinculado hasta el punto en que es difícil ubicar los límites de la incidencia existente entre ambos (VEGA, 2010; SCHUTZ, Y GURWITSCH, 1989).

\section{El discurso fotográfico capuchino del cuerpo de los niños mapuche}

El 6 de noviembre de 1895 se embarcaron en Hamburgo los cuatro primeros capuchinos bávaros que llegaron a La Araucanía: el sacerdote Anselmo de Kamin (futuro párroco de Boroa y fundador de Padre Las Casas), el sacerdote Félix José de Augusta (Médico de origen judío alemán), el sacerdote Tadeo de Wiessent (famoso por la aplicación del método hidroterápico) y el hermano Sérvulo de Gottmannshofen. Viajaron desde Hamburgo hasta Buenos Aires, y después a Santiago. Llegaron el 20 de diciembre. Luego viajaron a Valparaíso, donde el 4 de enero embarcaron en un vapor que los llevó a Corral. Desde 
ahí, el mismo día de su llegada viajaron en barco por río hasta Valdivia. Fueron recibidos por el párroco de Valdivia, José Brahm, quien se ocupó de los nuevos misioneros y les enseńó castellano durante seis semanas. El 16 de febrero de 1896 viajó el padre Félix con el hermano Sérvulo a Bajo Imperial (Actual Puerto Saavedra) en el espacio costero de La Araucanía. Hicieron a caballo el viaje por San José de la Mariquina y Toltén, se demoraron alrededor de 10 horas. Fueron recibidos por el padre Juan en Toltén. Descansaron unos días y los acompañó a Bajo Imperial, donde les hizo oficialmente entrega de la misión. Así se instalaban los capuchinos bávaros en la región de La Araucanía (RÖTTINGEN, 1921).

En este contexto, el Félix de Augusta le escribe por primera vez al Prefecto el 5 de marzo de 1896: "[...] difícil es saber qué hacer por el momento, sin la ayuda de hermanas para educar a los niños, no me prometo avances significativos" (RÖTTINGEN, 1921). Más tarde llegarán las hermanas de la Santa Cruz, haciendo eco de esta petición. En todas partes se abrieron escuelas misionales.

Los misioneros bávaros celebraron dos asambleas generales en 1901 y 1902 respectivamente, que pueden ser consideradas como asambleas constituyentes fundacionales de la misión bávara. En esas instancias debatieron y fijaron las normas del método para desarrollar la misión. Las normas plantean como tarea principal del misionero la enseñanza religiosa y la prédica del evangelio. Se planteó la necesidad de crear el mayor número posible de colegios misionales, actividad sustentada en tres pilares irrenunciables: (1) enseñanza profunda de la religión católica, (2) enseñanza de líneas de conducta corporal y, (3) instalación el hábito de una vida cristiana con frecuencia sacramental (RÖTTINGEN, 1921). Al llegar a La Araucanía, los capuchinos bávaros incorporaron la fotografía como forma de registro de sus procesos misionales. El propio Prefecto Bucardo señala que, en 1898, trajo consigo una cámara fotográfica al país (RÖTTINGEN, 1921, p.741).

Los capuchinos pertenecen a la "familia "franciscana y por tanto, son hijos de Francisco de Asís y seguidores de Cristo a la manera de Francisco. Como éste, comprenden y proyectan su labor misionera y evangelizadora, desarrollando una forma específica, aunque no exclusiva, de dicha tarea. Francisco señala que los religiosos deben ir "entre los sarracenos y otros infieles", el concepto central está dado en esta idea fuerza de ir entre y no ir. Así las cosas el misionero no puede ser sólo un peregrino o predicador ambulante debe ir a integrarse, incorporarse a la forma de vivir de los sarracenos e infieles (léase mapuches). Estar con, vivir entre, es la propuesta y desde allí anunciar el Evangelio (FLORES Y AZÓCAR, 2002). Para lograr 
tal cometido los capuchinos tuvieron que modificar las metodología de las misiones que hasta ese momentos había desarrollado los franciscanos a través de las denominadas "correrías apostólicas", fórmula que también practicaron los primeros capuchinos italianos que arribaron a La Araucanía a mediados del siglo XIX. Entonces, el método utilizado por los capuchinos bávaros se concretó a través de las "estaciones misionales estables", utilizando a la escuela y el internado como principales dispositivos. $\mathrm{Y}$ en esta tarea fueron importantes colaboradoras las religiosas de la congregación suizo-alemana de las Hermanas Maestras de la Santa Cruz, siendo unos de los propósitos de su acción pedagógico-evangelizadora la puesta en marcha de un proyecto biopolítico: su preocupación por la producción de la subjetivación de la familia burguesa (FOUCAULT, 1970; NOGGLER, 1972).

Dicho proyecto se encargó de gestar una división sexual que asigna a la mujer los roles de ama de casa, esposa y madre. Esta clasificación de labores, actividades y posiciones en la sociedad gana legitimidad a partir del discurso médico, el cual, a partir de las diferencias anatómicas y fisiológicas, justifica la necesidad de un tipo especial de educación para las mujeres (GOFFMAN, 1956; GÓMEZHERAS, 1989).

El cuerpo del misionero bávaro como agente preceptor se ocupa de vigilar e instruir criterios para el buen encauzamiento de los cuerpos de los otros, mientras que el cuerpo de las y los estudiantes se ocupará de escuchar, copiar y seguir al preceptor (REINACH, 1986).

En su tarea misionera, uno de los obstáculos centrales al que se vieron enfrentados los capuchinos bávaros, al igual que los italianos con anterioridad, fue la escasez de recursos humanos y financieros. Al parecer la fotografía se transformó en una estrategia para recaudar fondos, el texto en alemán permiten asumir que el mercado al que se dirigía era el de la Provincia Madre de Baviera. 
Foto 1 - Padre Félix de Augusta y niños mapuche en Bajo Imperial, 1899

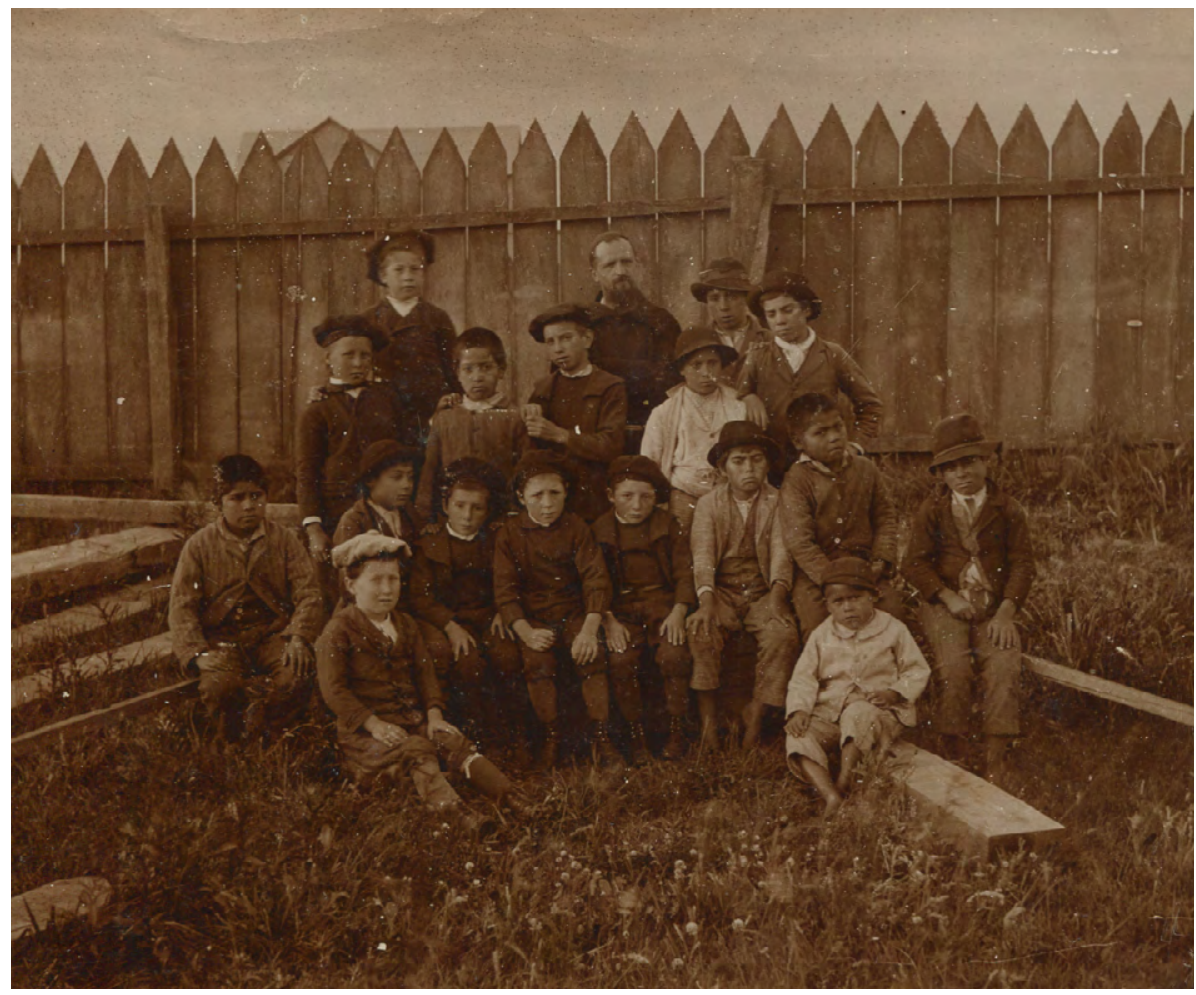

Fuente: Archivo Capuchino de Altötting, Baviera, Alemania.

Una lectura global del corpus, nos permite señalar que las fotografías impresas en las postales editadas por los capuchinos intentan mostrar la presencia permanente de éstos entre los mapuches, sobre todo entre los niños, quienes son presentados como sujetos posibles de transformación en el plano religioso y en el moral, es decir, posibles de convertir, en hombres de bien, en hombres de trabajo, desde la perspectiva de los misioneros. En casi la totalidad de las postales en que aparecen mapuches, están acompañados de religiosos. La expresión y actitud postural del cuerpo es rígido, tal vez porque están en un proceso de transición de un estado salvaje a un estado civilizado, ya no son completamente "indios", pero tampoco podemos decir que son completamente civilizado, indistintamente que ya estén vestidos con ropas de corte occidental (Foto 1).

En este contexto resulta pertinente plantear el proceso de disciplinamiento de los cuerpos y la fundación de una niñez dócil: 
[...] la producción corporal de la mujer y el hombre es un hecho fundacional de la modernidad. En el caso de la mujer, lo que en términos corporales se estableció como su naturaleza y logró traducirse en experiencias constitutivas de la subjetividad femenina devino soporte de las posibilidades de ser y decir de la mujer. (PEDRAZA, 2006, p. 77).

Foto 2 - Padre Leonardo con un grupo de niños en la Escuela Misional de Quilacahuin

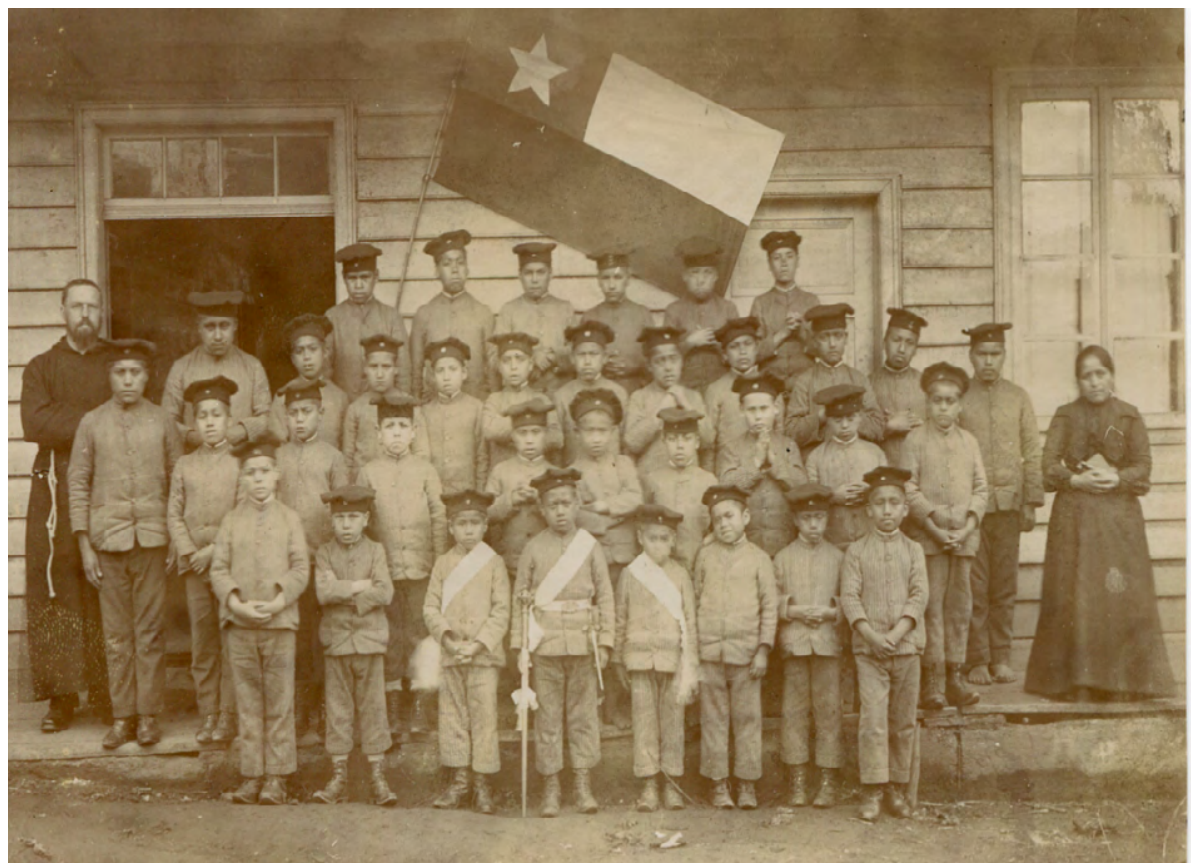

Fuente: Universidad Católica de Eichstätt-Ingolstadt, Alemania.

La bandera simboliza el concepto de patria y es fundamental para consolidar la idea de "Chile" entre los nińos mapuche, lo que se evidencia con la difusión del D. S. No 8364 del 22 de diciembre de 1925 que establecía las fechas de izamiento de la bandera nacional en las escuelas. Es el rol de "construcción de chilenos " desarrollado por la escuela. Como en todo tipo de texto, lo no dicho es también significativo en los mensajes visuales. En esta imagen no aparecen elementos de la cultura mapuche. Ni siquiera el vestuario de los alumnos nos recuerda que estamos frente a niños que pertenecen a esta etnia. Solo la lectura del texto del reverso escrito en alemán permite saberlo. Los niños son presentados como sujetos posibles de transformación en el plano religioso, moral, pedagógico. Es un 
discurso fotográfico construido desde una perspectiva eurocéntrica y colonialista. Un discurso que recrea la vieja dicotomía del buen y mal salvaje, mostrando un mapuche "evangelizable" y "civilizable" (FLORES Y AZÓCAR, 2015).

Foto 3 - Hermanas de la Santa Cruz, Panguipulli, 1936.

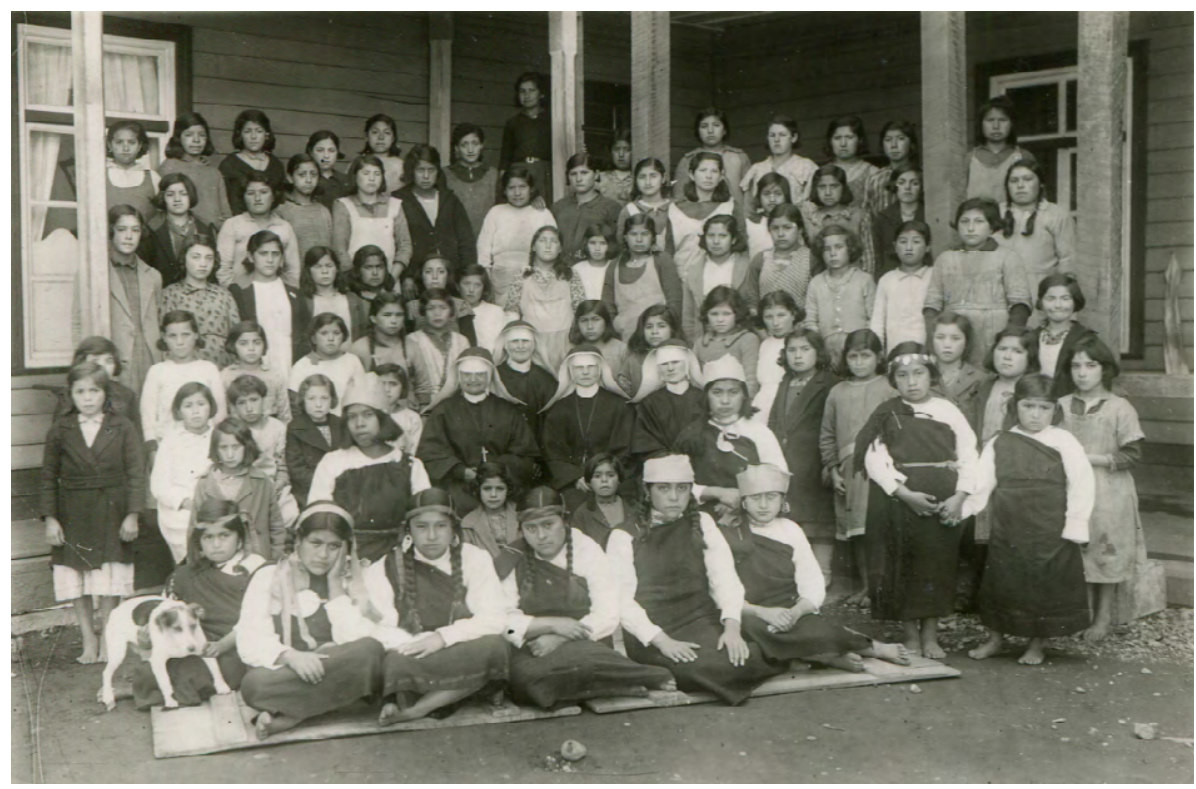

Las fotografías explotan la imagen del mapuche en clave folclorizante, acostumbrando al público a la idea de la desaparición. Fenomenológicamente nos instala en un incómodo lugar entre dos proto-sensaciones encontradas en las fronteras de la reminiscencia: el anuncio de una catástrofe futura, como el vértigo de un espectro que señala "ellas va a morir culturalmente" (muerte en futuro) y el noema de la fotografía que anuncia "esto ha sido y esto está siendo para que después sea de otro modo que ser" (BARTHES, 1989; MERNARD Y PÁVEZ, 2007; ALVARADO Y MÖLLER, 2011). Son registros que muestran el paso de un proceso civilizatorio entendido como evolución de la barbarie a la civilización. Muchos de los nińos y niñas fueron desvestidos y revestidos (Foto 3).

Entonces, junto al sarcófago apostasiado de la reducción de las tierras se agrega la reducción de los cuerpos en la pose. Es una construcción primitivista del otro, su compulsión por lo arcaico, que deshistoriza robando el tiempo que ha pasado. La fotografía serializa al sujeto subsumiéndolo bajo un nombre genérico y de amplias connotaciones épicas y mitológicas, "el araucano" un sujeto del pasado. 


\section{Conclusiones}

De otra parte, urgen investigaciones que den cuenta de las experiencias de cuerpo que viven los sujetos en nuestros contextos, pensados a la luz de pensadores diversos, incluyendo autores y autoras nacionales y latinoamericanos que maticen y enriquezcan nuestras concepciones sobre el cuerpo y la subjetividad.

Por último, es imprescindible recordar que la escuela es lugar del encuentro, del descubrimiento, del conocimiento, de las preguntas y de las sorpresas. Aunque en muchos casos también sea el lugar del temor, la confusión, los desencuentros y, en algunas ocasiones, del aburrimiento. Pero algo sí es muy claro: la escuela es el lugar donde muchos niños, niñas, jóvenes y adultos pasan un largo período de sus vidas. Además de ser el lugar donde se espera que se brinden experiencias y saberes que constituyan subjetividades creativas y con posibilidades de transformar su historia y la vida colectiva. En tanto la escuela siguesiendo unámbito degran importancia en nuestro modelo civilizatorio, caben todos los esfuerzos por comprenderla, reinventarla y, sobre todo, por abrir espacios para el goce, la creatividad y la potencia de la diversidad que no es otra cosa que la vida misma desplegando su hermosa complejidad. En escuelas tanto rurales como urbanas de contextos mapuches, la formación de niños y jóvenes se ha caracterizado por estar fundamentada en un curriculum escolar monocultural que ha negado el saber educativo mapuche (QUILAQUEO 2006; QUILAQUEO Y MERINO 2003; QUINTRIQUEO Y MCGINITY, 2009)

En la relación intersubjetiva que se produjo entre los capuchinos bávaros y el mundo de la niñez mapuche, no se generó un nosotros. Hubo un problema de acceso al otro. La filosofía de la conciencia nos hace caer en la trampa del otro ante mí. Un desafío es desmontar aquella trampa. Buscar una salida desde otro lugar que nos permita comprender los procesos de subjetivación. LO que hubo en esa relación asimétrica entre los bávaros y mapuches es una relación intersubjetiva donde unos fueron sujetos y otros objetos. El deseo político, psicoanalítico, epistemológico y religioso cara a cara no permitió ese reconocimiento. Encontramos al otro en las cosas, en las fotografías. Reaprendernos a encontramos desde ahí donde ya están las relaciones funcionando, es un desafío. Por tanto, lo que hace Merleau Ponty con este desplazamiento es dejar de hipostatizar, de poner fuera y por encima y con una sustancia propia al nosotros, para incorporar el nosotros como la dimensión común de nuestra propia vida, y aquí lo que queda tocado es la noción de individuo. Aprenderemos a decir nosotros cuando descubramos que ninguno de cada cual de nosotros puede ser un individuo. El nosotros lo vamos a encontrar cuando nos aprendamos a pensar como individuos imposibles. Esta es la gran lección de la estética de las fotografías presentadas. 
La filosofía de Merleau Ponty nos ayuda a acercarnos a esos abismos. Las fotografías nos muestran un hombre interior, el miedo. La interioridad no está oculta, sino entretejida con el mundo. Los elementos de la cultura mapuche están ausentes, salvo en contadas ocasiones en cada una de las fotografías. No es un mundo común el que se presenta. Los textos escritos en las postales refuerzan, y en algunos casos explicitan el mensaje de falta de recursos humanos y económicos para continuar con la obra civilizadora y evangelizadora que tan buenos resultados está logrando, a juzgar por las imágenes impresas.

\section{Referencias}

ALVARADO, M.; MÖLLER, C. Memoria visual e imaginarios. Fotografías de pueblos originarios. Siglos XIX-XXI. Santiago: Pehuén, 2011.

ARBOLEDA, R. Cuerpo y pedagogía. Revista Educación Física y Deporte, 19 (2), 83-91, 1997.

AZÓCAR, A.; NITRIHUAL, L.; FLORES, J.; LÓPEZ, S.; PACHECO, S. La tarjeta postal fotográfica y la escuela misional en La Araucanía: El discurso visual capuchino sobre sus logros en la transformación de la niñez mapuche (18981930). Revista Signa (24), 215-230, 2015.

BARBARAS, R. Le tournant de l'expérience. Recherches sur la philosophie de MerleauPonty. París: Vrin, 1998. 115p.

BARTHES, R. La cámara lúcida. Notas sobre la fotografía. Madrid: Paidós Ibérica, 1989. 165p.

BRAND, G. Die Lebenswelt. Eine Philosophie des konkreten a priori. Berlín: Walter de Gruyter, 1971.

BUBER, M. Yo y tú. Madrid: Caparrós, 1993.

CABRA, N.; ESCOBAR, M. El cuerpo en Colombia. Estado del arte cuerpo y subjetividad. Universidad Central, Bogotá: Instituto para la Investigación Educativa y el Desarrollo Pedagógico, IDEP, 2013.

DE LA BARRA, L. La pareja conceptual civilización-barbarie. Norte y Sur América. La novela indigenista de Lautaro Yankas. Ciberhumanitis, Chile, 14, 2000. Extraído de <http://web.uchile.cl/ publicaciones/cyber/14/tx6ldelabarra.html>.

FERNÁNDEZ-BEITES, P. Fenomenología del ser espacial. Salamanca: Universidad Pontificia de Salamanca, 1999. 
FLORES, J.; AZÓCAR, A. Tarjetas postales de los capuchinos. Revista Aisthesis, Santiago, (35), 81-88, 2002.

FLORES, J.; AZÓCAR, A. Evangelizar, civilizar y chilenizar a los mapuche. Fotografías de la acción de los misioneros capuchinos en La Araucanía. Temuco: Ediciones Universidad de La Frontera Editorial Universidad de Sevilla, 2015.

FOUCAULT, M. L'ordre du discours. Discurso inaugural en el Collège de France, 1970.

FOUCAULT, M. Vigilar y castigar. Nacimiento de la prisión. Buenos Aires: Siglo XXI editores, 2002.

GALLO, L. El ser-corporal-en-el-mundo como punto de partida en la fenomenología de la existencia corpórea. Pensamiento Educativo, Chile, (38), 46-61, 2006.

GOFFMAN, E. La presentación de la persona en la vida cotidiana. Buenos Aires: Amorrortu, 1956.

GÓMEZ-HERAS, J. M. El a priori del mundo de la vida. Fundamentación fenomenológica de una ética de la ciencia y de la técnica. Barcelona: Anthropos, 1989. GONZÁLEZ, R.; JIMÉNEZ, G. Fenomenología del entrecruce del cuerpo y el mundo en Merleau-Ponty. Revista Ideas y valores, Colombia, (145), 113-130, 2010.

LANDGREBE, L. El camino de la fenomenología. Traducción de Mario A. Presas. Buenos Aires: Sudamericana, 1968.

HOBSBAWM, E. Naciones y nacionalismos desde 1780. Barcelona: Siglo XXI editores, 1998.

HUSSERL, E. Ideas relativas a una fenomenología pura y una filosofía fenomenológica. México: Fondo de Cultura Económica, 1997. 213p.

HUSSERL, E. Lecciones de fenomenología de la conciencia interna del tiempo. Madrid: Trotta, 2002, p. 78.

HUSSERL, E. Ideas relativas a una fenomenología pura y una filosofía fenomenológica. Libro segundo: investigaciones fenomenológicas sobre la constitución. México: UNAM, 1997. 187p.

MANSILLA, J.; LLANCAVIL, D.; MIERES, M.; MONTANARES, E. Instalación de la escuela monocultural en la Araucanía, 1883-1910: dispositivos de poder y Sociedad Mapuche. Revista Educacao y Pesquisa, 42(1), 213-228, doi: 10.1590/S1517-9702201603140562 
MANSILLA, J.; HUAIQUIÁN, C. Enseñanza a la alemana: Transferencia del modelo de escuela de Berlín a Chile a fines del siglo XIX. Revista Espacios 39(17), 1-9, 2018. MAYORGA, R. Una red educativa, cuatro escuelas, millones de ciudadanos: educación, Estado republicano y sociedad civil en Chile (1813-2011). En Historia política de Chile. 1810-2010. Tomo II, Estado y sociedad. Santiago: Fondo de Cultura Económica, 2017.

MENARD, A.; PÁVEZ, J. Mapuche y anglicanos. Vestigios fotográficos de la misión araucana de Kepe, 1896-1908. Santiago: Ocho libro editores, 2007.

MERLEAU-PONTY, M. La prose du monde. Paris: Gallimard, 1969.

MERLEAU-PONTY, M. La fenomenología y las ciencias del hombre. Trad. Gonzalez-Piérola. Buenos Aires: Nova, 1969.

MERLEAU-PONTY, M. Fenomenología de la percepción [1945], Trad. Cabanes, J. Barcelona: Península, 2000.

MERLEAU-PONTY, M. Le visible et l'invisible. París: Gallimard, 1964.

NOGGLER A. Cuatrocientos ańos de misión entre los araucanos. Padre las Casas: Imprenta San Francisco, 1972.

PEDRAZA, Z. Modernidad y orden simbólico: cuerpo y biopolítica en América Latina. Aquelarre, 9, 93-108, 2006.

QUILAQUEO, D.; MERINO, M. Estereotipos y prejuicio étnico hacia los mapuches en textos complementarios a la asignatura de Historia. Campo Abierto, 23, 119-135, 2003.

QUILAQUEO, D. Valores educativos mapuches para la formación de persona desde el discurso de kimches. Estudios Pedagógicos, 32(2):73-86, 2006.

QUINTRIQUEO, S.; MCGINITY, M. Implicancias de un modelo curricular monocultural en la construcción de la identidad sociocultural de alumnos/as mapuches de la IX región de La Araucanía, Chile. Estudios Pedagógicos 35(2), 173-188, 2009.

RAMOS. JA. Cuerpo y carne en la filosofía de M. Merleau-Ponty. Tesis doctoral Departamento de Filosofía Facultad de Filosofía de la UNED, 2015.

RAMÍREZ, M. El quiasmo. Ensayos sobre la filosofía de Maurice Merleau Ponty. México: Universidad Michoacana de San Nicolás de Hidalgo, 1994.

REINACH, A. Introducción a la fenomenología. Madrid: Encuentro, 1996. 
RÖTTINGEN, B. Crónica de la Prefectura Apostólica de La Araucanía, 1896-1921. Tomos I y II. Documento mecanografiado, 1921.

SERRANO DE HARO, A. La posibilidad de la fenomenología. Madrid: Complutense, 1997.

SCHUTZ, A.; GURWITSCH, A. Philosophers in Exile.The correspondence of Alfred Schutz and Aron Gurwitsch, 1939-1959. Bloomington, Indianópolis: Indiana University Press, 1989.

TAYLOR, C. H. Philosophical Arguments. Cambridge, Mass: Harvard University Press, 1995.

TODOROV, T. La conquista de América, el problema del otro. México DF.: Siglo XXI editores, 1987.

VEGA, V. Cuerpo, diálogo y educación: una aproximación desde la fenomenología. Bogotá: CINDE, 2010.

WANDENFELS, B. De Husserl a Derrida. Introducción a la fenomenología. Barcelona: Paidós, 1997. 